\title{
Deluge of typhoons may aid forecast models
}

\section{David Cyranoski, Kobe}

More than a hundred people have been killed by natural disasters in Japan in a little over a week. A magnitude 6.8 earthquake and severe aftershocks hit the western coastal region of the country, only days after an unusually violent typhoon ripped across the other coast.

Although seismologists continue to argue over the possibility of predicting earthquakes (see News Feature, page 1032), climatologists in Japan definitely see the 20 October typhoon as part of a trend. They are studying the footprint of the event to work out whether Japan is experiencing a short-term upward fluctuation in cyclone activity - or a more ominous, long-term increase linked to global warming.

Typhoons are like hurricanes but they emerge in the northwestern Pacific rather than the Atlantic. Both are intense tropical cyclones that form in low atmospheric pressure systems and give off winds travelling at more than 32 metres per second.

Last week's typhoon, which killed more than 80 people, was the 23 rd such storm to be tracked by Japanese meteorologists in 2004. This is not an abnormally high number, but ten of these cyclones have come ashore, compared with an average of two or three a year since 1951, when modern records began. And four of them gave off winds of 40 metres per second when they hit Japan. The size of the typhoons and the amount of rain accompanying them is "super-abnormal", says Yoshio Kurihara, a typhoon specialist with the Frontier Research
Center for Global Change in Yokohama.

Kurihara says that higher average air pressures over the western North Pacific and higher sea surface temperatures are probably contributing to the severity of the typhoons.

But working out why that is will require greater knowledge of the structure of the typhoon, particularly of the "wall around the eye", where the wind is strongest and most of the storm's energy is released, says Kurihara. This wall varies in size, but its outer radius is normally about 40 kilometres and it can be 20 kilometres deep.

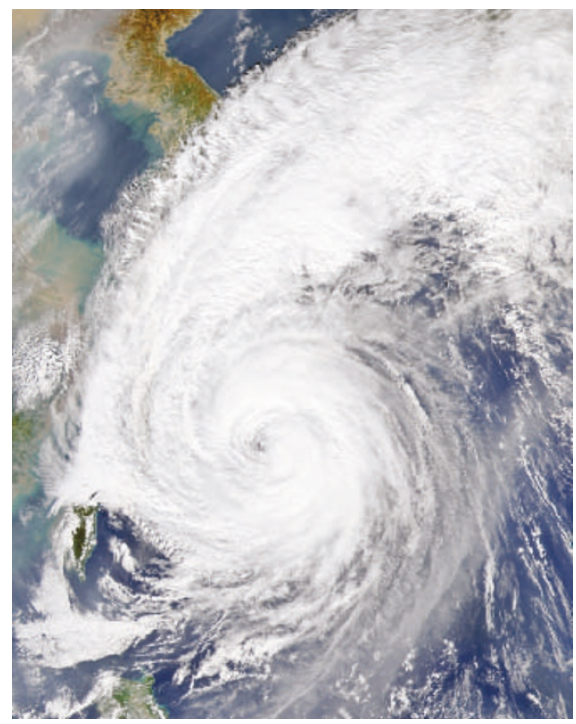

Heart of darkness: the cyclonic storm that hit Japan's Pacific coast last week took a heavy toll.
Unlike their counterparts in the United States, Japanese meteorologists lack aircraft that are capable of monitoring storm centres directly. They rely on a combination of satellite observation and ground-based monitoring to measure water vapour, wind speed, temperature and pressure around the centres. Kurihara and others are hoping that data from this year's storms can be compared with results from models of typhoons and the wider global climate system, and will lead to improvements in the models.

Akira Hasegawa, also of the Frontier centre, says that their model on the Earth Simulator - Japan's most powerful supercomputer - suggests that increased levels of carbon dioxide in the atmosphere will lead to lower or constant typhoon frequencies, with more rain. "If global warming continues, we will get typhoons with increasingly torrential rains," Hasegawa says.

This year's pattern would seem to confirm that prediction. But, Kurihara says, "it's too early to make any definite connections with global warming". Big typhoons were also observed in the 1950s, he notes.

This year's data will also be used to improve weather forecasts. Three days before the typhoon hit, the Japan Meteorological Agency made a landing-site prediction that was within 360 kilometres of the actual site and forecasted wind strengths that were only slightly weaker than those observed. "It was one of our better ones," says Nobutaka Mannoji, the head of the agency's typhoon division.

\section{Generic drugs allowed in global trial of AIDS therapy}

\section{Erika Check, Washington}

Patients taking generic drugs will be permitted to participate in a worldwide trial that aims to find the best way to treat AIDS using antiretroviral medicines, US government officials say.

On 7 October, the scientific advisory board of Community Programs for Clinical Research on AIDS (CPCRA) voted to allow generic drugs to be used in its largest study. The trial, called Strategies for Management of Anti-Retroviral Therapy (SMART), is expected to include some 6,000 patients and to last a decade.

Officials at the US National Institutes of Health (NIH), which is funding the trial, say that the advice to include generic drugs has been accepted. "We're saying that the use of generic drugs in some countries in the study would not compromise the science," says Sandra Lehrman, director of the Therapeutics Research
Program at the NIH's Division of AIDS.

The United States does not allow its foreign aid to be used for buying generic drugs until they have been approved by the US Food and Drug Administration. Although the SMART trial does not fund the purchase of drugs, doctors in some countries said earlier this year that the NIH had decided that patients using generic drugs would not be able to take part in SMART. Doctors and AIDS activists criticized this decision, alleging that it was driven by the political clout of US drug companies, rather than by good medical practice (see Nature 431, 493; 2004).

The CPCRA says it will now consider enrolling patients who are taking generic drugs in the trial "on a country by country and drug by drug basis". Countries will be required to submit evidence that the drug they want to use has been approved by their own regulators. The CPCRA is now talking to at least one country that would use generic drugs - Brazil - about its participation in SMART.

But it remains uncertain when, or if, other countries will join the trial, which will test alternative strategies for when patients should be treated with antiretrovirals. Enrolment in SMART is already behind schedule: only $40 \%$ of the patients expected to enrol this year have been signed up, and critics say the new policy leaves uncertainties in place that might increase delays.

But Martin Delaney of the non-profit AIDS foundation known as Project Inform, who is a member of the CPCRA advisory board, says the policy is a reasonable compromise. A broader approval for all generic drugs would be unwise, he says: "There are so many possible sources of drugs getting into the international AIDS drug market that it would be impossible to simply issue a blanket approval." 